\title{
Correspondence
}

\section{Special Committee on Political Abuse of Psychiatry}

DeAR SiR,

Dr Levine's report of the Special Committee on the Political Abuse of Psychiatry (Bulletin, May 1981, p. 94) was welcome, and it is good to know that the College has been so active in the defence of individuals who are the victims of such abuse, and that it has addressed our colleagues in the USSR so directly on these matters. I hope, however, that the College will not fall into the trap of seeming to suggest that the 'first-rank' symptoms of oppression are confined to one country, however fashionable such a view may be. That this is a risk is suggested by the strange comment that the differentiation in standards of psychiatric care according to skin colour in South Africa is 'not considered to be primarily political'. What is considered political is ultimately a political decision; for example, to come nearer home, if psychiatrists were called upon to advise on civil defence or on life in the post-nuclear warfare age, would those responding be acting responsibly and professionally, or would this represent (as I believe) a political abuse, serving to prepare the minds of people to accept the idea that the unthinkable horror of nuclear warfare is not unthinkable?

While I hope the College will sustain its role in relation to psychiatry in the USSR, I believe that the Committee, even if necessarily 'empowered to act independently', should consult very fully with the members on these matters, and should show a proper breadth and impartiality in its concern with abuse, as does, for example, Amnesty International. Until then we should not settle down too snugly and smugly under Edmund Burke's mantle.

University of Sussex

ANTHONY RYLE

Brighton

\section{Obstacles and rivals}

DEAR SIR

I was interested to read Norman Imlah's letter 'An obstacle to in-patient treatment' (April, 1981, p. 72), with his experience of problems in working with the Social Services Department, particularly in the matter of compulsory admission of patients to hospital under the Mental Health Act. We too, in the York area, have had problems precisely of the kind that Dr Imlah describes, particularly from the younger social worker, whose theoretical training seems to be somewhat out of touch with the realities of the duties of a mental welfare officer! However, it is hoped that this is a teething problem resulting from the reorganization to the generic social worker which occurred a few years ago, and that as those social workers gain experience, they will become more pragmatic.

This problem, however, seems to me to be symptomatic of a more general difficulty in the relationships between established professions, particularly, in this context, medicine and psychiatry, and the professions which are establishing themselves in related fields.

We have found particular difficulty in the last year or two in our relationship with our clinical psychology colleagues, and this would seem to be primarily the fault of the Trethowan report, or perhaps its over-enthusiastic application.

Clinical psychology, having at one time been a profession that worked within the psychiatric hospital and under the umbrella of consultant psychiatry cover, has now become a district-based service doing its own thing, which in practical terms seems to mean that it has set up as a rival therapeutic group practising its own brand of therapy, and in competition with the established NHS psychiatric service.

Indeed, a rival therapeutic team is now in our area giving sessional time at health centres and direct referrals are being made for treatment by general practitioners to these nonmedically qualified therapists, presumably with the general practitioner continuing to take the legal responsibility for the patient. In practice this is leading to a demarcation dispute where it would seem that the clinical psychologists now consider that they are the experts in the treatment of neuroses, and that psychiatrists should confine themselves to psychotic illness and the dementias!

I cannot think that these trends are healthy to psychiatry as a profession, since our own caseloads are absurdly large in contrast to those currently accepted by the other professions (clinical psychology and social work), resulting in fact in our probably giving a poorer service, but being unable to expand our own professional team because of financial constraints.

It would seem to me that the implications of the Trethowan report were not really thought through at the time, and that the way in which the situation is developing is something which should be causing psychiatrists a considerable disquiet. I wonder if other readers have similar experiences.

\section{Clifton Hospital}

M. T. HAsLAM

York YO3 6RD

\section{DeAR SIR}

\section{Police use of hypnosits}

I have been asked to prepare a list of professional people interested in attending a seminar at the Home Office early in September on the vexed question of the use of hypnosis in 